\title{
On the coupling of water cycle components
}

\author{
J. D. Martínez-Nájera \\ Comisión Federal de Electricidad, Mexico
}

\begin{abstract}
The natural dynamics of the hydrologic cycle involves the exchange of water, substances, and energy between the atmosphere, soil surface, biota, interflow zone, and aquifer subsystems. The dynamics is governed by physical laws and is powered by the sun; however, today it is also necessary to consider the action of man on the natural dynamics. The purpose of this paper is to present a conceptual physical framework for the study of the component subsystems of the hydrological cycle, which allows the development of integrated mathematical models. It is assumed that each subsystem is governed by its own field equations of balance of mass, energy and constitutive relationships, and that these are related by coupling terms, all of them following the maximum entropy principle, that drives the processes and subsystems to equilibrium thermodynamic states. Keywords: hydrologic cycle, field balance equations, maximum entropy principle, equilibrium states, hydrologic parameters, water supply.
\end{abstract}

\section{Introduction}

The natural behavior of the hydrologic cycle is governed by physical laws, the surface, capillary and ground water interacts with the thermodynamics of the atmosphere; as well as with the land form, geology, and biotic factors, they all influence each other [1-3]. The dynamics is influenced by the uses of land and water, the quality of water is affected for the discharges into water bodies, and atmospheric emissions [4], unbalanced water consumption diminishes the water availability [5-7]; human uses and activities have implications in the environment and climate change. Bronstert et al. [8] consider that the processes in the atmosphere, biosphere, hydrosphere and geosphere are coupled. The water, energy, and biogeochemical cycles act over a wide range of spatial and temporal scales [1-3]. The cycle, or at least parts of it, is sensitive to climate changes (warming of the lower atmosphere will cause evaporation increase, thereby 
increasing rainfall [8]). Acting together the water, energy, and biogeochemical cycles generate spatial and temporal patterns in the atmosphere, biosphere, hydrosphere and geosphere that have the general appearance of, or at least tending to, stable equilibrium [1-4, 8]. Nearly all surface water systems like streams, lakes, reservoirs, wetlands, estuaries, the contained in the biota, and in the interflow interacts with ground water and atmospheric water in many forms $[1,3,9]$. The withdrawal of water from rivers, streams and lakes can deplete ground water or conversely, pumpage of ground water can diminish water availability in surface water $[10,11]$. Pollution in surface water causes degradation of ground water quality and conversely; atmospheric emissions can alter the quality of the rainwater, hail and snow, the source terms for the surface, interflow and ground waters. The sustainable use of water requires the consideration of integrators schemes of natural behavior and the effect of regulatory aspects on the hydrological cycle. Effective land and water management requires a clear understanding of the physical linkages of water between the different subsystems; regarding them as manifestations of a single resource [9, 12-14]. Model development permits to analyze problems otherwise intractable: to simulate natural processes of the flow of water, sediment, chemicals, nutrients, and microbial organisms in watersheds, as well as quantify the impact of human activities on these processes [15].

The purpose of this work is to present a physical framework for the study of the coupling of the subsystems of the hydrological cycle; which allows the development of integrated mathematical models to analyze the flow of water and substances in the different components. Under the hypothesis that each subsystem is interacting with the others, governed by its own field equations, the coupling terms could be boundary conditions and/or transference field relations; all of them obeying the maximum entropy principle that drives the processes and subsystems to equilibrium thermodynamic states.

\section{Subject and brief history of distributed modelling}

Singh and Frevert [15] present a compendium of existing models for watershed modeling that span a wide range of characteristics, such as: environmental and water resources problems (planning, development, design, operation, and management); flooding and droughts; upland, streambank, and coastal erosion; sedimentation; water pollution from industrial, domestic, and agricultural sources; migration of microbes; salinity and alkalinity of soils; deterioration of lakes; acid precipitation; disappearance of beaches; desertification and degradation of land; decay of rivers and aquifers; effects of irrigation of agricultural lands, and land uses; proper management of water resources; conjunctive use of surface and groundwater; reliable design of hydraulic structures; the analysis for river rectification; impact of climate change on water resources; water allocation; recreational, ecological, and biological concerns to compete with traditional consumptive uses, such as agriculture, hydropower, municipality, and industry [16]; and quantification of the impacts of watershed management strategies linking human activities to water quantity and quality 
$[17,18]$ for environmental and water resources protection. These will be some of practical problems which could be solved using watershed hydrologic models.

According to Kampf and Burges [19], some of the earliest hydrologic models were forms of the rational method used to convert rainfall rates to estimates of runoff [18] based on the work of Mulvany [21]; then in the early 20th century the hydrologic models consisted of empirical formulas or modified forms of the rational method $[22,23]$. By the 1970s, hydrologic models were well-established tools, and the types of modeling approaches had begun to proliferate. To sort existing models numerous classification schemes have been proposed [25-27]; to take into account the effects of terrain slope the hillslope models were developed. Hydrologic distributed models are considered as the art state [19]. Advances in watershed models [15] have occurred since the first attempt to model the hydrologic cycle, Stanford Watershed Model [24], and the outstanding work of Freeze and Harlan [28]. Examples of such watershed hydrology models are: Storm Water Management Model [29], Precipitation-Runoff Modeling System [30], National Weather Service River Forecast System [31], Streamflow Synthesis and Reservoir Regulation [32], Systeme Hydrologique Europeen [33, 34], TOPMODEL [35], Institute of Hydrology Distributed Model [36].

\section{Framework of distributed models}

Freeze and Harlan proposed a first summary for the development of physically based hydrologic response models [19, 28], as well as Abbott et al. [33, 34]; considering the hydrological cycle as a dynamical system that operates according to conservative physical laws that derives its energy from sun radiation, the balance equations together boundary conditions define the hydrologic model. Storage elements, transmission routes, and decision points are physically based, figure 1. The precipitation is considered as the input, the evapotranspiration in empirical forms as output, for the canopy interception they consider empirical relationships. For the flow through porous media the equation of continuity combined with Darcy's law is [28],

$$
\frac{\partial}{\partial x}\left[\rho K(x, y, z) \frac{\partial \varphi}{\partial x}\right]+\frac{\partial}{\partial y}\left[\rho K(x, y, z) \frac{\partial \varphi}{\partial y}\right]+\frac{\partial}{\partial z}\left[\rho K(x, y, z) \frac{\partial \varphi}{\partial z}\right]=\rho \frac{\partial \theta}{\partial t}+\theta \frac{\partial \rho}{\partial t}
$$

where $x, y, z$ are the spatial coordinate directions ( $z$ is the head elevation); $t$ time; $\rho$ the density of fluid; $K(x, y, z)$ the permeability of porous medium; $\varphi=\psi+z$ the total hydraulic head; $\psi \geq 0$ the pressure head (saturated); $\psi \prec 0$ the soil moisture tension head (unsaturated); $\theta$ the moisture content (unsaturated); $\theta$ the porosity (saturated). With the equation is possible to represent steady or unsteady saturated or unsaturated flow, for compressible or incompressible fluid through a non-homogeneous, anisotropic porous medium.

Abbot et al. [33, 34] developed the SHE to address hydrological studies related to the impact of man's activities on land use change and water quality; their model is physically based, where each component of the hydrological cycle 
is modeled in a separate component: interception, by the Rutter procedure; evapotranspiration, by the Penman-Monteith equation; overland and channel flow, by simplifications of the St. Venant equations; unsaturated flow, by the Richards equation; saturated zone flow, by the two-dimensional Boussinesq equation; snowmelt, by an energy budget method. The computer code is realized in modular form so that improvements or additional components can be added.

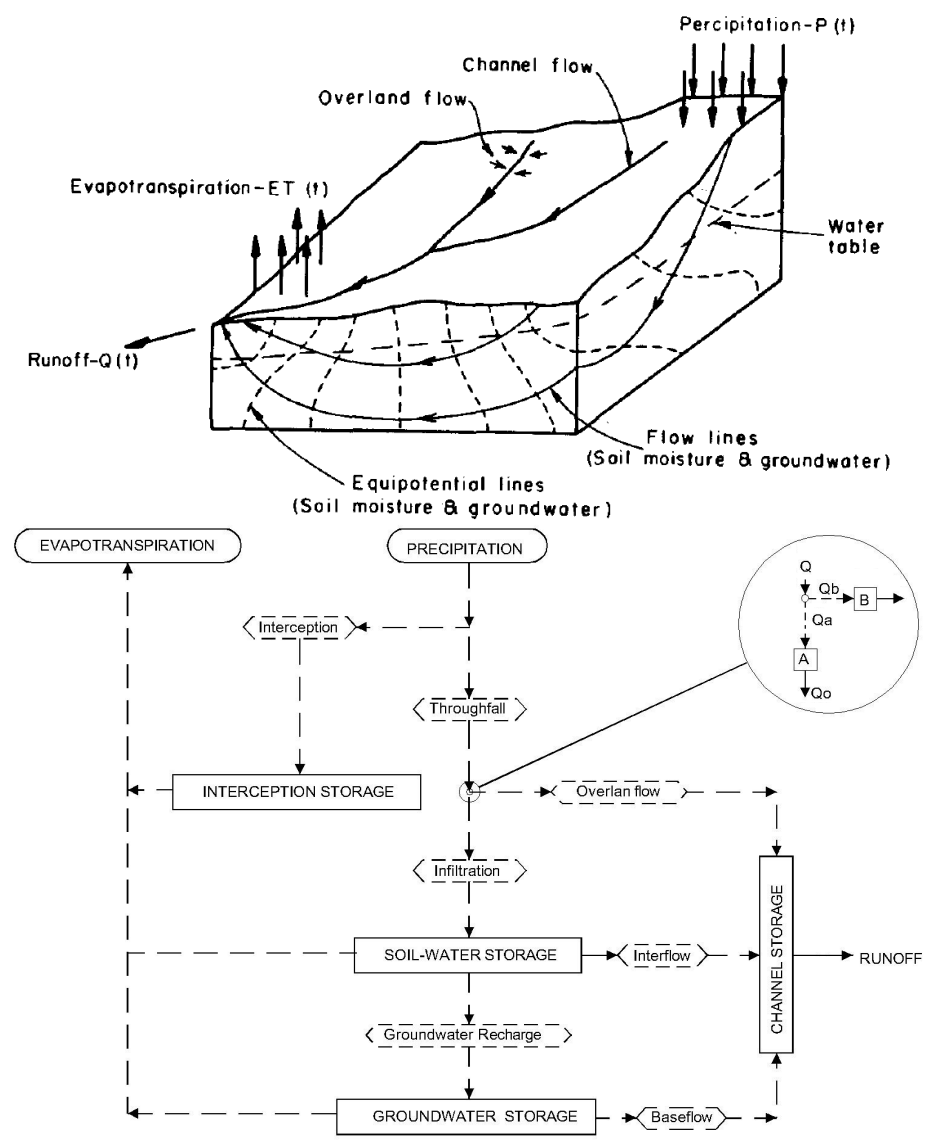

(a)

Figure 1: (a) Natural basin; and (b) dynamic system (after Freeze and Harlan [28]).

\section{Proposed framework}

The proposed framework is similar to that of Freeze and Harlan [28], and by Abbott et al. [33, 34], but emphasizing that each individual subsystem or component of the hydrologic cycle constitutes a dynamic system that interacts dynamically with the other with its own field equations and coupling terms, all under the auspices of thermodynamics principles. The literature has many similar works, but most consider the problem with no general explicit physical frame, or 
address the issue rather partially. The intention of this draft is to give a first broadly approach on the subject, among others can be found exceptional works that address the problem in [3-6, 8-10, 12, 14, 15, 18, 35].

By the action of sun heat, the sea water (and surface) passes into the atmosphere, then returning to the land and the sea (and surface); the direction or sense can be reversed at any step of the cycle, obeying physical dynamic laws of transference, figure 2; the figure 1b outlines the involved mechanisms.

Physically the transference of energy, water, and substances in atmosphere, surface, biota, capillary zone, and aquifers may be considered separately in each subsystem obeying his field balance equations. When water and substances move from one subsystem to another, it does so by coupling terms which join and determine the exchange rates; the coupling terms could be boundary conditions, which also specifies the relations of subsystems whit their exterior. Moreover almost all the nonequilibrium or time dependent processes described by the field balance equations for mass and energy transference in the hydrological cycle, may be irreversible, but must satisfice the thermodynamic entropy maximum principle (EMP), [37], that drives the systems to equilibrium states; considering that the entropy of each subsystem is a function of the extensive parameters of that subsystem only, and their additivity property. In the transit to equilibrium subsystems also obey the thermodynamic potentials defined for each subsystem. This is the sense of the proposed approach.

In practice field balance equations and coupling terms are supplied with data, parameters and geometric characteristics that determine each subsystem, as well as by the corresponding boundary conditions, which could form part of the coupling terms, figure 2; numerical (or analytical) procedures are then applied to solve the proposed basin hydrological setting.

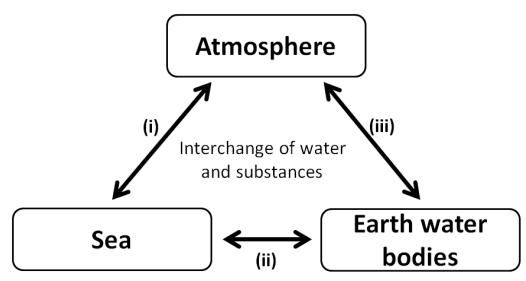

(a)

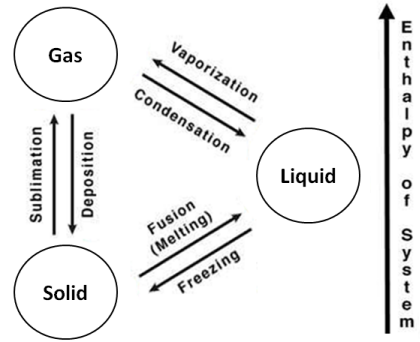

(b)

Figure 2: (a) Movement of water and substances in the hydrologic cycle; and (b) Phase transitions between gases (highest enthalpy), liquids (intermediate enthalpy), and solids (lowest enthalpy).

\subsection{The field balance equations}

The natural laws of transference of momentum and substances between components of the cycle obey similar forms based on Cauchy's field equations and mass balance [38], respectively. Biota can follow their own patterns; in the same way social, political, statutory, or economic issues can follow their own 
behavioral patterns; but as long as they are in balance form, not necessarily conservative, then it is possible to couple these behaviors with the natural laws of the movement of water and substances in the hydrological cycle, given rise to new kind of coupling schemes [39-43]. The way in which of Cauchy's equations appear is in their specialization to Newtonian fluids (incompressible fluids with constant viscosity, exhibiting friction through shear forces, describing isochoric processes at constant density). Their explicit form is commonly known as the Navier-Stokes (NS) equations,

$$
\rho_{0}\left[\mathbf{v}^{\prime}+(\operatorname{grad} \mathbf{v}) \mathbf{v}\right]=\mu \Delta \mathbf{v}-\operatorname{grad} \pi+\mathbf{b} \text {, and } \operatorname{div} \mathbf{v}=0
$$

The last relation is the incompressibility condition. Given the constant viscosity $\mu$, the density $\rho_{0}$, and the body forces $\mathbf{b}$; the NS constitute a system of nonlinear partial differential equations for the velocity $\mathbf{v}$ and the pressure $\pi$. In Newtonian fluids rotation varies with time, at rest behaves as ideal fluids. The NS equations establish the balance of momentum and can be complemented by the general law of mass balance (MB), as in [44],

$$
\frac{\partial \rho}{\partial t}+\operatorname{div}(\rho \mathbf{v})+\operatorname{div}\left(-\mathbf{K}_{\rho} \nabla \rho\right)=g(\mathbf{x}, t, \rho, \nabla \rho)
$$

where $\rho(\mathbf{x}, t)$ is the density, $\mathbf{v}$ is the velocity, $\mathbf{K}_{\rho}$ is a tensor of order zero or two, which indicates the rate at which the system returns to equilibrium (in nonequilibrium linear theory, is some kind of Fick's law); and $g$ represents the sources and sinks for $\rho$.

Both NS and MB appear in multiple ways in the study of hydrological systems in separate or mixed forms, e.g. in the St. Venant's equations in surface flows, Richards equation in the flow in capillary zone, Boussinesq equation for water waves, in the flow through porous media eqn (1) in combination with Darcy's law (which can be derived from NS equations, Whitaker [45]); so too water vapor in atmosphere obeys the full NS and MB equations under temperature, pressure, and other thermodynamic potentials, including the EMP.

Both NS and MB are directed as in a symphony by the EMP. The EMP also drive the thermodynamic potentials of heat transference, pressures distribution, mechanical principles, mole fractions interchange, chemical reactions, phase changes, and magnetic dipole moment interactions; all these accompany the dynamics of transference under the NS and MB equations. The EMP directs the whole evolution of systems toward states in which the properties are determined by intrinsic factors and not by previously applied external influences; such simple terminal states are, by definition, time independent, and they are called equilibrium states [37].

\subsection{The fundamental equation}

Entropy $S$ is additive, also is function of the extensive parameters of each subsystem only, and is postulated only for equilibrium states. In absence or 
removal of constraints, or after external forces, the system spontaneously selects and goes to the state of maximum entropy. Eqn (4a) is known as the fundamental equation, and contains all thermodynamic information about the system [37],

$$
S=S\left(U, V, M, I, N_{1}, \ldots, N_{r}\right), \quad \text { and } \quad U=U\left(S, V, M, I, N_{1}, \ldots, N_{r}\right)
$$

where $U$ is the internal energy, which is an extensive macroscopic parameter conservative, controllable and measurable; $V$ is the volume of system; $M$ the appropriate extensive mechanical parameters (kinetic and potential energy, and dissipative mechanical terms); $I$ the magnetic dipole moment of the system; and $N_{1}, \ldots, N_{r}$ are the mole numbers. In terms of energy (4b) the EMP imply an extremum principle in terms of minimum of energy (rather than a maximum of the entropy). From the fundamental equation it is possible to derive the relations for Enthalpy, Helmholtz and Gibbs free energy, Landau potential relevant in practical hydrological settings. In mechanics and electricity the energy is function of various mechanical or electrodynamical parameters; but if thermal effects are included the energy (4b) is also function of entropy, and the energy minimum principle is extended to the domain of thermal effects as well as to pure mechanical or electrodynamical phenomena. In this manner there is a sort of correspondence principle between thermodynamics and mechanics [37], ensuring that thermodynamic equilibrium principle reduces to the mechanical equilibrium principle when thermal effects can be neglected. From eqn (4b),

$$
\begin{aligned}
d U=\left(\frac{\partial U}{\partial S}\right)_{V, M, I, N_{1}, \ldots, N_{r}} d S+\left(\frac{\partial U}{\partial V}\right)_{S, M, I, N_{1}, \ldots, N_{r}} d V \\
\quad+\left(\frac{\partial U}{\partial M}\right)_{S, V, I, N_{1}, \ldots, N_{r}} d M+\left(\frac{\partial U}{\partial I}\right)_{S, V, M, N_{1}, \ldots, N_{r}} d I+\sum_{j=1}^{r}\left(\frac{\partial U}{\partial N_{j}}\right)_{S, V, M, I} d N_{j}
\end{aligned}
$$

The partial derivatives appearing in the previous equation are the intensive parameters: the temperature $\mathrm{T}$, pressure $\mathrm{P}$, mechanical parameters $\mathrm{M}$ (kinetic, potential, and dissipation terms), the external magnetic field $B_{e}$, the electrochemical potential of the jth component $\mu_{j}$, repectively. Under the EMP temperature can be looked upon as a sort of potential for heat flux and pressure as a potential for volume changes, similarly mechanical parameters can be a sort of potential of mechanical and heat dissipation interactions, the external magnetic field as a potential for electrodynamics interactions, so the chemical potential can be looked upon as a sort of potential or generalized force for matter flow, phase changes, and chemical reactions.

Then under transitory states the systems evolve spontaneously to equilibrium, following a path indicated by the field equations NS-MB, dissipation and viscous forces, inelastic collisions, and the indicated by the thermodynamic potentials (5); the whole evolution of systems toward equilibrium states is directed by the EMP. 


\section{Some explicitness in the hydrologic cycle modelling}

Jutla [46] presents a watershed analysis related in some sense with this work, and uses a system dynamics approach. The Jutla work is also related with the blueprint of Freeze and Harlan [28] and the SHE structure proposed by Abbot et al. [33, 34]. GEOTOP model of Bertoldi and Rigon [47] show a physical structure, also intimately related whit the concepts of the present work.

Explicitly according with the presented physical approach, the behavior and fate of water and substances in the atmosphere, sea, and earth water bodies, as well as in their coupling interactions types, indicated in figure 2a by (i)-(iii), follows the thermodynamic laws EMP-NS-MB, dissipation-viscous irreversible terms, as well as thermodynamic potentials of fundamental equation (5).

In figure 2a type (i) and (iii) coupling interactions can be related with water phase changes (figure $2 b$ ) driven by the sun's heat transfer, and by mechanical wind advection-diffusion, turbulent terms, and by chemical potential (Fick's and Fourier's laws). It could be possible that the evapotranspiration and precipitation terms are the most important terms; for the precipitation time series of meteorological measurements, statistical approaches, satellite data or isohyetal maps [28] can be used. Evapotranspiration presents a major difficulty in its determination, due is highly variability over a drainage basin and with time [28, 47, 34]; their components depend on the land cover complexes [48, 49], hydrologic soil groups and land use [49], atmospheric pressure and the air temperature [49-50], solar radiation (shortwave and longwave) and shadows [51], atmospheric attenuation [52], topographic aspects [2], etc. Type (ii) interactions refer to water and substances interchange between sea and earth water bodies, as the rivers and riparian water bodies. The prevailing relations are the NS-MB, and thermodynamic potentials in different presentations, densitydriven and water flow can occur with thermal components $[1,4,6,10,25,46$, 47, 53].

As in the coupling interactions, figure 2a by (i)-(iii), when water and substances moves in the atmosphere, sea, and earth also naturally follows the thermodynamic laws EMP-NS-MB, but specialized for each subsystem. The atmosphere behavior can be described by full EMP-NS-MB equations [46-48, $50,51]$, while sea dynamics can be described by the averaged or full 3D NS-MB equations $[4,8,9,20,25,33,34]$. The movement of water in earth can be separated into the components of surface, and capillary and saturated zones; their analysis is carried out with the specialization of the NS-MB equations [1-3, 610, 13-15, 20, 23, 25, 27-31, 33-35, 46, 47, 52, 53].

\section{Conclusions}

It is proposed conceptual physical framework for the study of the subsystems of the hydrological cycle and their coupling, with the approach it is possible eventually build mathematical models of each of the subsystems in a rather integrated manner, to analyze the flow of water and substances in the different components of the cycle; also it is possible to couple behavioral patterns of biota 
systems; also management strategies from social, political, statutory, or economic issues, as long as they are in balance form. The proposed framework consists of the field equations NS and MB, constitutive relationships, dissipation terms, as well as thermodynamic potentials implicit in the fundamental equation; all of them following the maximum entropy principle, that drives the processes and subsystems to equilibrium thermodynamic states.

\section{References}

[1] Sophocleous, M., Interactions between groundwater and surface water: the state of the science. Hydrogeology Journal, 10, pp. 52-67, 2002.

[2] Rodríguez-Iturbe, I. and Valdés, J.B., The geomorphologic structure of hydrologic response. Water Resour. Res., 15(6), pp. 1409-1420, 1979.

[3] Cruickshank-Villanueva, C., Relación entre las aguas superficiales y las subterráneas en una cuenca. Ing. Hid. en México, VII(1/3), pp. 56-63, 1992.

[4] Ji, Z.G., Hydrodynamics and water quality. Modeling rivers, lakes, and estuaries, Wiley Interscience, 676 pp., 2007.

[5] USEPA, Handbook for developing watershed plans to restore and protect our waters, US Environmental Protection Agency, 400 pp., 2008.

[6] Sophocleous, M., Global and regionalwater availability and demand: prospects for the future. Natural Resour. Res., 13(2), pp. 61-75, 2004.

[7] Tuinhof, A. and Heederik, J.P., Management of aquifer recharge and subsurface storage. Making better use of our largest reservoir, NNC-IAH Pub. 4, 106 pp., 2003.

[8] Bronstert, A., Carrera J., Kabat P. and Lütkemeier, S., Coupled models for the hydrological cycle. Integrating atmosphere, biosphere, and pedosphere, Springer Berlin Heidelberg, NY, 345 pp., 2005.

[9] Winter T.C., Harvey J.W., Franke O.L. and Alley, W.M., Ground water and surface water a single resource, USGS Circular 1139, 87 pp., 1998.

[10] Martínez-Nájera, J.D., Cruickshank-Villanueva, C. and BerezowskyVerduzco, M., Evaluation of the interaction between rivers and aquifers for water supply. River Basin Management VI, WIT Transactions on Ecology and the Environment, ed. C.A. Brebbia, 146, pp. 15-23, 2011.

[11] Jenkins, C.T., Computation of rate and volume of stream depletion by wells, USGS, Techniques of Water Resources Investigations, 21 pp., 1977.

[12] USEPA, (ed). Proceedings of the ground-water/surface-water interactions workshop, US Environmental Protection Agency, 71 pp., 2000.

[13] Barton, G.J., Surface-and ground-water relations on the Portneuf river, and temporal changes in ground-water levels in the Portneuf valley, Caribou and Bannock counties, Idaho, 2001-02, USGS, Scientific Investigations Report 2004-5170, 59 pp., 2004.

[14] Tinker, S.W., John, A. and Katherine, G., Groundwater surface water interactions in Texas, Bureau of Economic Geology, Jackson School of Geosciences, University of Texas, Austin, Texas, USA, 240 pp., 2005.

[15] Singh V.P. and Frevert D.K., Watershed models, Taylor \& Francis Group, 637 pp., 2006. 
[16] Hickey, J.T. and Diaz, G.E., From flow to fish to dollars: An integrated approach to water allocation. J. Am. Water Resour. Assoc., 35(5), pp. 10531067, 1999.

[17] Mankin, K.R., Koelliker, J.K. and Kalita, P.K., Watershed and lake water quality assessment: An integrated modeling approach. J. Am. Water Resour. Assoc., 35(5), pp. 1069-1088, 1999.

[18] Rudra, R.P., Dickinson, W.T., Abedini, M.J. and Wall, G.J., A multi-tier approach for agricultural watershed management. J. Am. Water Resour. Assoc., 35(5), pp. 1059-1070, 1999.

[19] Kampf, S.K. and Burges, S.J., A framework for classifying and comparing distributed hillslope and catchment hydrologic models. Water Resour. Res., 43, 2007.

[20] Singh, V.P. and Woolhiser, D.A., Mathematical modeling of watershed hydrology. J. Hydrol. Eng., 7, pp. 270-292, 2002.

[21] Mulvany, T.J., On the use of self-registering rain and flood gauges. Trans. Inst. Civ. Eng. Ireland, 4, pp. 1-8, 1851.

[22] Dooge, J.C.I., Rational method for estimating flood peaks. Engineering, 184, pp. 374-377, 1957.

[23] Todini, E., Rainfall-runoff modeling-Past, present and future. J. Hydrol., 100, pp. 341-352, 1988.

[24] Crawford, N.H. and Linsley, R.K., Digital simulation in hydrology: Stanford watershed model IV, Rep. 39, Civ. Eng., Stanford Univ., CA, 210 pp., 1966.

[25] Singh, V.P., (ed). Watershed modeling. Computer Models of Watershed Hydrology, Water Resour. Publ., CO., pp. 1-22, 1995.

[26] Refsgaard, J.C., Terminology, modelling protocol and classification of hydrological model codes. Distributed hydrological modeling, eds. M.B. Abbott and J.C. Refsgaard, Springer, NY, pp. 17-39, 1996.

[27] Clarke, R.T., A review of some mathematical models used in hydrology, with observations on their calibration and use. J. Hydrol., 19, pp. 1-20, 1973.

[28] Freeze, R.A. and Harlan, R.L., Blueprint for a physically-based, digitallysimulated hydrologic response model. J. Hydrol., 9, pp. 237-258, 1969.

[29] Metcalf and Eddy Inc., Univ. of Florida \& Water Resour. Engineers Inc., Storm water management model, Vol. 1-Final report, EPA Report, 1971.

[30] Leavesley, G.H., Litchy, R.W., Troutman, B.M. and Saindon, L.G., Precipitation runoff modeling system-User's manual, USGS Water Resour. Investigations Report, 1983.

[31] Burnash, R.J.C., Ferral, R.L. and McGuire, R.A., A generalized streamflow simulation system-conceptual modeling for digital computers, US Dep. of Comm., Nat. Weather Serv. and State of CA, Dep. of Water Resour., 1973.

[32] Rockwood, D.M., Theory and practice of the SSARR model as related to analyzing and forecasting the response of hydrologic systems. Applied Modeling in Catchment Hydrology, ed. V.P. Singh, pp. 87-106, 1982.

[33] Abbott M.B., Bathurst J.C., Cunge J.A., O'Connell P.E. and Rasmussen J., An introduction to the European Hydrological System - Systeme 
Hydrologique Europeen, "SHE", 1: history and philosophy of a physicallybased, distributed modelling system. J. Hydrol., 87, pp. 45-59, 1986.

[34] Abbott M.B., Bathurst J.C., Cunge J.A., O'Connell P.E. and Rasmussen J., An introduction to the European Hydrological System - Systeme Hydrologique Europeen, "SHE", 2: structure of a physically-based, distributed modelling system. J. Hydrol., 87, pp. 61-77, 1986.

[35] Beven, K.J. and Kirkby, M.J., A physically-based variable contributing area model of basin hydrology. Hydrol. Sci. Bull., 24(1), pp. 43-69, 1979.

[36] Morris, E.M., Forecasting flood flows in grassy and forested basins using a deterministic distributed mathematical model, IAHS 129, pp. 247-255, 1980.

[37] Callen, H.B., Thermodynamics and an introduction to thermostatistics, John Wiley \& Sons, 493 pp., 1985.

[38] Gurtin, M.E., An introduction to continuum mechanics, Academic Press, NY, 265 pp., 2003.

[39] Gorelick, S.M., A review of distributed parameter groundwater management modeling methods. Water Resour. Res., 19(2), pp. 305-319, 1983.

[40] Aguado, E., Optimization techniques and numerical methods for aquifer management, Ph.D. Dissertation, Stanford Univ., Stanford, CA, 1979.

[41] Illangasekare, T. and Morel-Seytoux, H.J., Stream-aquifer influence coefici-ents as tools for simulation and management. Water Resour. Res., 18(1), 1982.

[42] Jones, L.C., Willis, R. and Yeh, W.W., Optimal control of nonlinear ground-water hydraulics using diferential dynamic programming. Water Resour. Res., 23(11), 1987.

[43] Mays, L.W. and Tung, Y.K., Hydrosystems engineering and management, McGraw-Hill Inc., NY, 1992.

[44] Martínez-Nájera, J.D., Simulación numérica de problemas de control asociados a la ecuación hiperbólico-parabólica de advección-difusión, M.Sc. thesis, Univ. Nat. Autonomous of México, 100 pp.,1992.

[45] Whitaker, S., Flow in porous media I: A theoretical derivation of Darcy's law. Transport in Porous Media, 1, pp. 3-25, 1986.

[46] Jutla, A.S., Hydrologic modeling of reconstructed watersheds using system dynamics approach, M.Sc. thesis, Univ. of Saskatchewan, Can., 187 pp, 2006.

[47] Bertoldi, G. and Rigon, R., GEOTOP a hydrological balance model, technical description and programs guide, Università Degli Studi di Trento, Ingegneria Civile e Ambientale, Technical Report DICA-04-001, 102 pp., 2004.

[48] Deardorff, J.W., Efficient prediction of ground surface temperature and moisture with inclusion of a layer of vegetation. J. of Geophysical Res., 83(C4), pp. 1889-1903, 1978.

[49] USDA-Natural Resour. Conservation Service, Part 630 Hydrology, National Engineering Handook, Chapters 4,7,8,9, and 12, 2004. 
[50] Brutsaert, W., Evaporation into the atmosphere: theory, history and applications, Kluver Academic Publisher, 316 pp., 1982.

[51] Iqbal M, An introduction to solar radiation, Academic Press, 223 pp., 1983.

[52] Eagleson, P.S., Dynamic hydrology, McGraw-Hill, 462 pp., 1970.

[53] Bear, J., Dynamics of fluids in porous media, Elsevier, NY, 764 pp., 1972. 